\title{
Beyond Conventional Therapy: Role of Pulse Steroids in Bleomycin Induced Lung Injury
}

\author{
Raghav Gupta MD and Neil A Ettinger MD
}

\section{Introduction}

Bleomycin is an anti-neoplastic agent with potential for producing pulmonary toxicity, attributed in part to its freeradical-promoting ability. The central event in the development of toxicity is endothelial damage of the lung vasculature due to bleomycin-induced cytokines and free radicals, ultimately progressing to lung fibrosis. The treatment is discontinuation of bleomycin, initiation of systemic glucocorticoid therapy, and carefully titrating supplemental oxygen. Once the conventional therapy fails and the requirement of oxygen increases, pulse steroids have been associated with clinical, physiological, and radiographic resolution of bleomycin-induced lung disease.

\section{Case Summary}

A 65-year-old woman presented with progressive dyspnea on exertion. Six months before presentation she was diagnosed with stage IV Hodgkin lymphoma and treated with 4 cycles of ABVD (doxorubicin, bleomycin, vinblastine, and dacarbazine). The patient received a total dose of 126 units of bleomycin, and her last cycle of chemotherapy was given a week before presentation. She denied fever, chills, chest pain, or cough, and did not recall any relevant exposures, recent travel, or change in medications. Her family history was unremarkable. The patient also reported no smoking history. On physical examination she was alert and oriented, with normal vital signs. Her $\mathrm{S}_{\mathrm{pO}_{2}}$ was $88 \%$ while breathing ambient air. Diminished respiratory excursion and bibasilar crackles were noted on physical examination, which was otherwise unremarkable. Cardiac auscultation found no murmurs or

\footnotetext{
Dr Gupta is affiliated with the Department of Internal Medicine, and Dr Ettinger is affiliated with the Department of Pulmonary, Critical Care, and Sleep Medicine, St Luke's Hospital, Chesterfield, Missouri.
}

The authors have disclosed no conflicts of interest.

Correspondence: E-mail: drraghav11@gmail.com.

DOI: $10.4187 /$ respcare. 02560 irregularities. Her white blood cell count was $2,200 / \mu \mathrm{L}$, with a shift to the left in the differential (55\% neutrophils, $16 \%$ lymphocytes, $14 \%$ bands, $8 \%$ monocytes, $6 \%$ metamyelocytes, and $1 \%$ eosinophils), because she was recovering from chemotherapy. The erythrocyte sedimentation rate was $96 \mathrm{~mm} / \mathrm{h}$. Other blood cell counts, electrolytes, renal, and liver function tests were unremarkable. An arterial blood gas analysis showed $\mathrm{pH} 7.46, \mathrm{P}_{\mathrm{CO}_{2}} 38 \mathrm{~mm} \mathrm{Hg}$, and $\mathrm{P}_{\mathrm{O}_{2}} 68 \mathrm{~mm} \mathrm{Hg}$ on room air.

Chest radiography showed bilateral pulmonary infiltrates (Fig. 1), and computed tomography revealed bilateral peripheral interstitial infiltrates, fibrosis, and patchy groundglass infiltrates, with no evidence of pulmonary embolism (Fig. 2). Complete pulmonary function testing was not performed because of her clinical deterioration. Bedside pulmonary function testing indicated a very severe restrictive defect: FVC $0.74 \mathrm{~L}$ ( $21 \%$ of predicted), $\mathrm{FEV}_{1} 0.72 \mathrm{~L}$ (27\% of predicted), and $\mathrm{FEV}_{1} / \mathrm{FVC}$ of $97 \%$ of predicted. She was presumed to have bleomycin-induced lung injury, on the basis of clinical, radiographic, and pulmonary function test findings. In consideration of her clinical status, rather than a low dose of intravenous methylprednisolone $(1 \mathrm{mg} / \mathrm{kg} / \mathrm{d})$, she was started on a dose of $60 \mathrm{mg}$ every 8 hours, together with an anti-oxidant, and $\mathrm{N}$-acetylcysteine in oral or nebulized form. Supplemental oxygen was delivered via nasal cannula, to maintain $\mathrm{S}_{\mathrm{pO}_{2}}$ of $89-92 \%$. To obtain biopsies we conducted fiberoptic bronchoscopy, which revealed acute lung injury, type II pneumocyte hyperplasia, thickened alveolar walls, areas of increased interstitial cellularity, intra-alveolar fibrin, and fibroblast aggregates, which suggests a mixed pattern of organizing pneumonia and interstitial pneumonitis. There was no substantial alveolar or interstitial eosinophilia. Acid-fast bacilli, fungal, and pneumocystis staining were negative for microorganisms. Cytology was negative for malignancy.

Within 1 week her breathing difficulty and oxygen requirement increased, requiring admission to the ICU, at which time arterial blood analysis showed $\mathrm{pH}$ 7.47, $\mathrm{P}_{\mathrm{CO}_{2}} 44 \mathrm{~mm} \mathrm{Hg}, \mathrm{P}_{\mathrm{O}_{2}} 48 \mathrm{~mm} \mathrm{Hg}$, and oxygen saturation $83 \%$ while on oxygen at $15 \mathrm{~L}$. Oxygen flow was increased to $30 \mathrm{~L}$ (Optiflow, Fisher \& Paykel Healthcare, Auckland, New Zealand) to maintain an adequate oxygen saturation. 


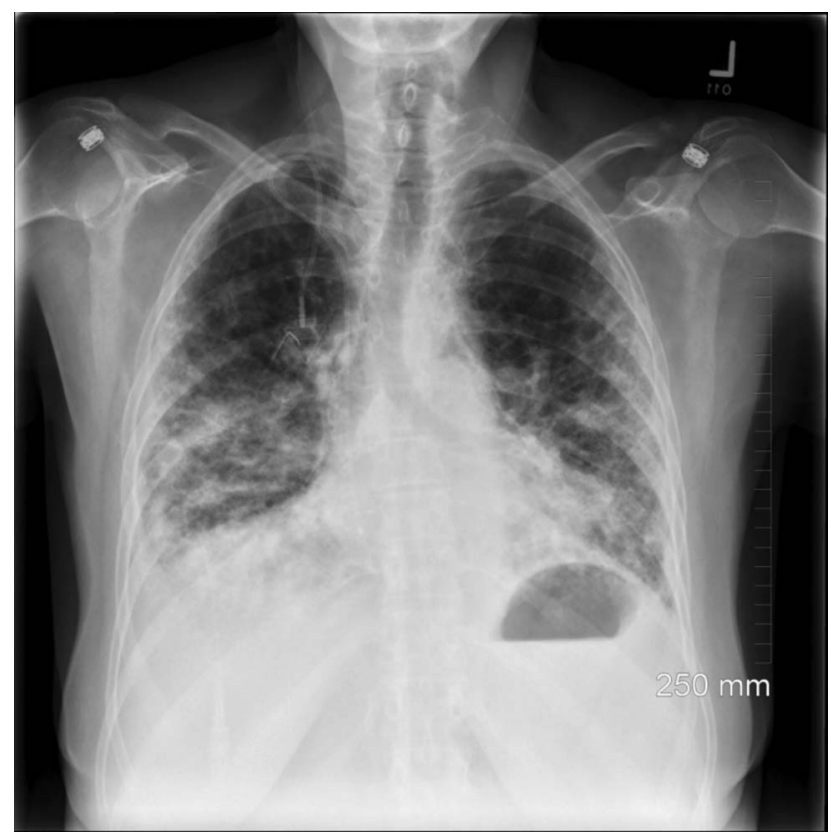

Fig. 1. Chest x-ray shows bilateral peripheral pulmonary infiltrates, with no evidence of pleural effusion or pneumothorax.

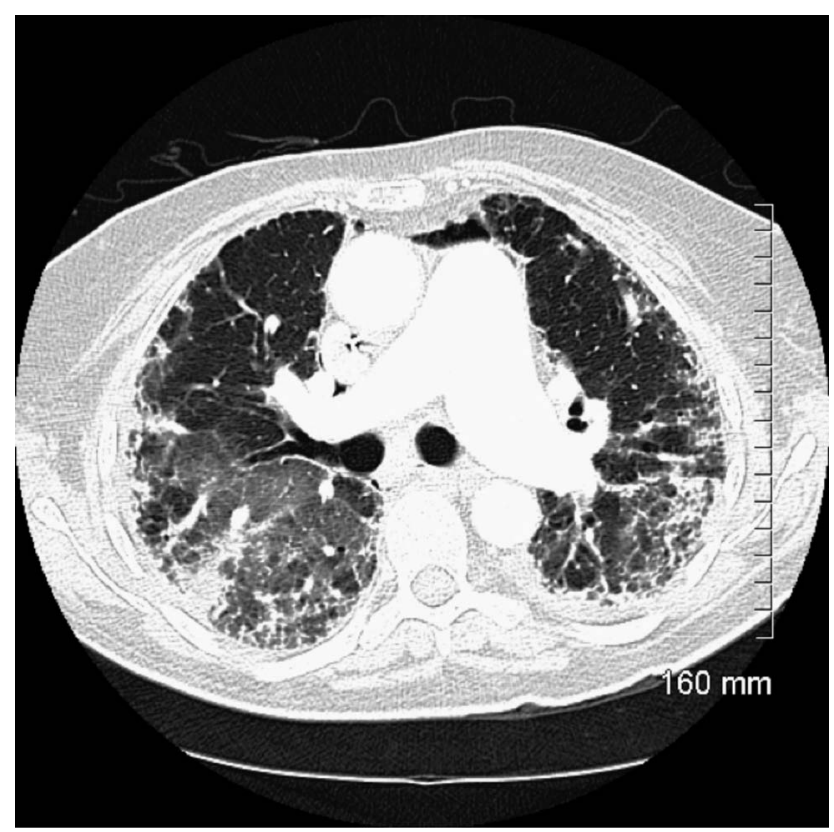

Fig. 2. Computed tomography at admission shows bilateral interstitial pulmonary infiltrates, fibrosis, and patchy ground-glass infiltrates.

In light of the failure of standard therapy after 1 week, she was started on pulse corticosteroid therapy, with methylprednisolone, $1 \mathrm{~g}$ intravenously every day. Following 12 days of methylprednisolone her oxygen requirement improved from $30 \mathrm{~L} / \mathrm{min}$ to $6 \mathrm{~L} / \mathrm{min}$, via nasal cannula. A week later she showed remarkable clinical improvement,

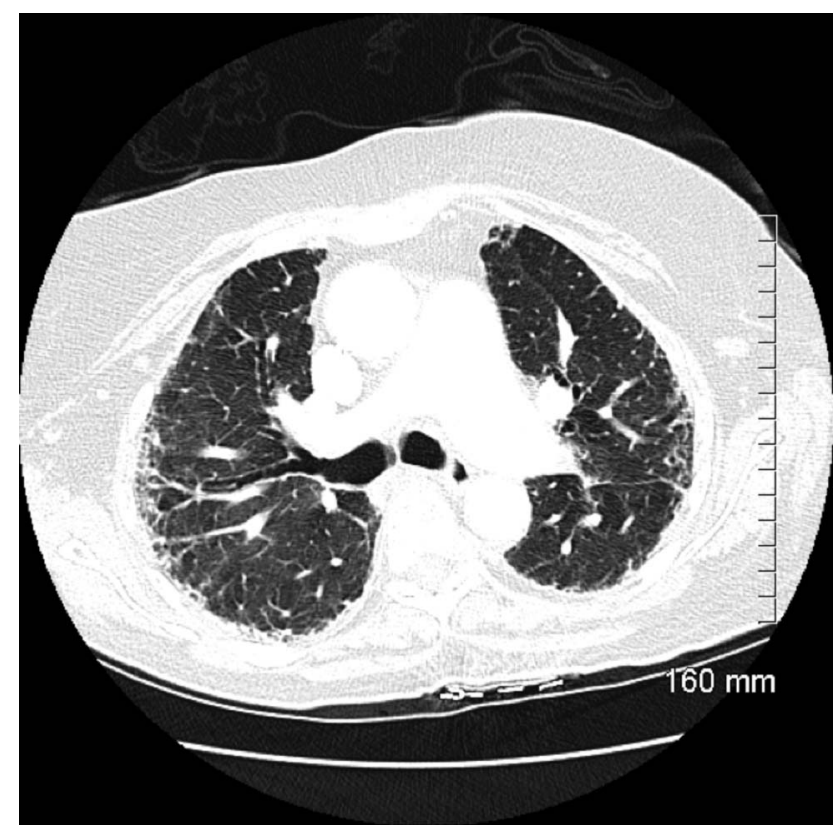

Fig. 3. Follow-up computed tomography after pulse steroids treatment shows bilateral mild interstitial markings, with improvement of the peripheral interstitial pulmonary infiltrates and patchy groundglass infiltrates.

requiring only $1 \mathrm{~L} / \mathrm{min}$ of oxygen to maintain adequate saturation, and she was discharged to an acute rehabilitation center. She showed continuous improvement of symptoms on a tapering schedule of steroids, and was kept on a maintenance dose of oral prednisone, $5 \mathrm{mg}$ daily. Computed tomography 1 month later showed improvement of bilateral infiltrates in the lung bases, but persistent fibrosis (Fig. 3).

\section{Discussion}

Bleomycin has a well established role in the management of Hodgkin lymphoma (the ABVD and BEACOPP [bleomycin, etoposide, adriamycin doxorubicin, cyclophosphamide, oncovin/vincristine, procarbazine, prednisone] regimens) and testicular germ cell tumors (BEP [bleomycin, etoposide, platinum] regimen). ${ }^{1,2}$ Pulmonary toxicity is one of the major drawbacks of bleomycin; as many as $20 \%$ of patients develop interstitial fibrosis. ${ }^{3}$ Other forms of bleomycin-induced lung injury include interstitial pneumonitis, organizing pneumonia, and hypersensitivity pneumonitis. ${ }^{4-6}$ Although lung injury is commonly associated with high bleomycin cumulative doses of over 400 units, it has also been reported with low doses of less than 50 units. $^{7}$ Though the exact mechanism by which bleomycin results in lung injury is unclear, free-radicalinduced oxidation is considered the primary mechanism. ${ }^{8}$ The relative deficiency of the bleomycin-inactivating en- 
zyme bleomycin hydrolase in the lung is also considered contributory, and several studies in mice have suggested a role for immune-mediated lung injury. ${ }^{9}$

Patients receiving a higher cumulative dose of bleomycin, concomitant therapy with other anti-neoplastic agents or radiotherapy, and high $\mathrm{F}_{\mathrm{IO}_{2}}$ have a higher risk of bleomycin-induced lung injury. ${ }^{10-12}$ Cigarette smoking and advanced age are also risk factors. Symptoms associated with bleomycin lung injury are often nonspecific and often develop a few months following therapy. ${ }^{13}$ These patients commonly present with dry cough, chest pain, dyspnea, fever, tachypnea, bilateral auscultatory crackles, and hypoxemia. However, the onset of symptoms tends to be more acute and rapidly progressive. A history of treatment with bleomycin and absence of pulmonary involvement by either malignancy or infection are prerequisite for a diagnosis of bleomycin-induced lung injury. ${ }^{14} \mathrm{~A}$ low diffusion capacity of the lung for carbon monoxide and flowvolume loops indicating a restrictive pattern (decreased FVC and total lung capacity) support the diagnosis. ${ }^{15,16}$ High-resolution computed tomography of the chest can demonstrate ground-glass opacities, subpleural nodules, linear reticular markings, or honeycombing and traction bronchiectasis, depending on the underlying pathology and chronicity of disease. ${ }^{17,18}$

Histopathological changes in bleomycin inducedinterstitial pneumonitis include type I pneumocyte necrosis, type II cell hyperplasia, and polymorphonuclear leukocytic infiltration. Bleomycin-induced organizing pneumonia, on the other hand, is characterized by the presence of budding granulation tissue within the alveolar air space. ${ }^{19}$ Hypersensitivity pneumonitis, a rare variant of bleomycin-induced lung injury, is associated with eosinophilic infiltration and mild interstitial fibrosis. ${ }^{6}$

Discontinuation of bleomycin is the first step in the management of bleomycin-induced lung injury, and reinitiation of bleomycin is permanently avoided in these patients. Intravenous corticosteroid $(0.75-1 \mathrm{mg} / \mathrm{kg} / \mathrm{d}$, using ideal body weight) is often recommended. ${ }^{4}$ Benefit with $\mathrm{N}$-acetylcysteine, an anti-oxidant administered orally or in a nebulized form, has also been reported in case studies. ${ }^{20,21}$ Steroids are tapered after $4-8$ weeks in patients showing response. Careful titration of supplemental oxygen to maintain $\mathrm{S}_{\mathrm{pO}_{2}}$ between $89 \%$ and $92 \%$ is recommended, because there is strong evidence of a synergistic effect between previous bleomycin exposure and subsequent exposure to high $\mathrm{F}_{\mathrm{IO}_{2}}$ in inducing lung injury. ${ }^{22}$

Pulse corticosteroid therapy involves a short duration of intermittent supra-pharmacologic doses $(0.5-2 \mathrm{~g})$ of methylprednisolone. Favorable outcomes with pulse steroids to treat lung injury caused by various anti-neoplastic agents (eg, gefitinib, irinotecan, panitumumab, and erlotinib) are well documented. ${ }^{23-25}$ There are reported cases that support the use of pulse steroids in bleomycin-induced lung injury, with remarkable clinical and radiographic responses. ${ }^{26,27}$ The time to improvement in these reports varied widely, ranging from 7 to 12 days. Bloor et al reported 2 fatal cases of bleomycin pneumonitis in which the patients were initiated on moderate doses of steroid and high-dose steroid therapy was not administered until later. ${ }^{28}$ Those reports suggest a possible benefit with early initiation of high-dose steroid therapy.

Our patient had success with pulse steroid therapy. Contrary to prior case reports, she had a dramatic improvement in clinical status, with the oxygen requirement decreasing from $30 \mathrm{~L} / \mathrm{min}$ to $6 \mathrm{~L} / \mathrm{min}$ within 48 hours. We recommend pulse steroid therapy in patients whose oxygen requirement increases despite conventional steroid therapy.

\section{Teaching Points}

- Lung injury is a common complication of bleomycin, and can be acute or chronic.

- Avoid high $\mathrm{F}_{\mathrm{IO}_{2}}$ in these patients, because it may worsen the lung injury.

- Pulse steroid therapy has a potential role in refractory bleomycin pneumonitis.

\section{REFERENCES}

1. Peckham MJ, Barrett A, Liew KH, Horwich A, Robinson B, Dobbs $\mathrm{HJ}$, et al. The treatment of metastatic germ-cell testicular tumours with bleomycin, etoposide and cis-platin (BEP). Br J Cancer 1983; 47(5):613-619.

2. Bauer K, Skoetz N, Monsef I, Engert A, Brillant C. Comparison of chemotherapy including escalated BEACOPP versus chemotherapy including ABVD for patients with early unfavourable or advanced stage Hodgkin lymphoma. Cochrane Database Syst Rev 2011;(8): CD007941.

3. Kinjo T, Tomaru K, Haines DC, Klinman DM. The counter regulatory response induced by $\mathrm{CpG}$ oligonucleotides prevents bleomycin induced pneumopathy. Respir Res 2012;13:47.

4. White DA, Stover DE. Severe bleomycin-induced pneumonitis. Clinical features and response to corticosteroids. Chest 1984;86(5): 723-728.

5. Garrido M, O’Brien A, Gonzalez S, Clavero JM, Orellana E. Cryptogenic organizing pneumonitis during oxaliplatin chemotherapy for colorectal cancer: case report. Chest 2007;132(6):1997-1999.

6. Yousem SA, Lifson JD, Colby TV. Chemotherapy-induced eosinophilic pneumonia. Relation to bleomycin. Chest 1985;88(1):103-106.

7. Quigley M, Brada M, Heron C, Horwich A. Severe lung toxicity with a weekly low dose chemotherapy regimen in patients with non-Hodgkin's lymphoma. Hematol Oncol 1988;6(4):319-324.

8. Sleijfer S. Bleomycin-induced pneumonitis. Chest 2001;120(2): 617-624.

9. Filderman AE, Genovese LA, Lazo JS. Alterations in pulmonary protective enzymes following systemic bleomycin treatment in mice. Biochem Pharmacol 1988;37(6):1111-1116.

10. Tryka AF, Skornik WA, Godleski JJ, Brain JD. Potentiation of bleomycin-induced lung injury by exposure to $70 \%$ oxygen. Morphologic assessment. Am Rev Respir Dis 1982;126(6):1074-1079.

11. Tryka AF, Godleski JJ, Brain JD. Differences in effects of immediate and delayed hyperoxia exposure on bleomycin-induced pulmonary injury. Cancer Treat Rep 1984;68(5):759-764. 


\section{Beyond Conventional Therapy: Role of Pulse Steroids in Bleomycin Induced Lung Injury}

12. Haas CD, Coltman CA Jr, Gottlieb JA, Haut A, Luce JK, Talley RW, et al. Phase II evaluation of bleomycin. A Southwest Oncology Group study. Cancer 1976;38(1):8-12.

13. Uzel I, Ozguroglu M, Uzel B, Kaynak K, Demirhan O, Akman C, et al. Delayed onset bleomycin-induced pneumonitis. Urology 2005; 66(1):195.

14. Flieder DB, Travis WD. Pathologic characteristics of drug-induced lung disease. Clin Chest Med 2004;25(1):37-45.

15. Jensen JL, Goel R, Venner PM. The effect of corticosteroid administration on bleomycin lung toxicity. Cancer 1990;65(6):1291-1297.

16. Ng AK, Li S, Neuberg D, Chi R, Fisher DC, Silver B, et al. A prospective study of pulmonary function in Hodgkin's lymphoma patients. Ann Oncol 2008;19(10):1754-1758.

17. Shofer S, Badea C, Qi Y, Potts E, Foster WM, Johnson GA. A micro-CT analysis of murine lung recruitment in bleomycin-induced lung injury. J Appl Physiol 2008;105(2):669-677.

18. Bellamy EA, Husband JE, Blaquiere RM, Law MR. Bleomycinrelated lung damage: CT evidence. Radiology 1985;156(1):155-158.

19. Beasley MB, Franks TJ, Galvin JR, Gochuico B, Travis WD. Acute fibrinous and organizing pneumonia: a histological pattern of lung injury and possible variant of diffuse alveolar damage. Arch Pathol Lab Med 2002;126(9):1064-1070.

20. Cort A, Ozdemir E, Timur M, Ozben T. Effects of N-acetyl-Lcysteine on bleomycin induced oxidative stress in malignant testicular germ cell tumors. Biochimie 2012;94(12):2734-2739.
21. Li S, Yang X, Li W, Li J, Su X, Chen L, et al. N-acetylcysteine downregulation of lysyl oxidase activity alleviating bleomycininduced pulmonary fibrosis in rats. Respiration 2012;84(6):509-517.

22. Gilson AJ, Sahn SA. Reactivation of bleomycin lung toxicity following oxygen administration. A second response to corticosteroids. Chest 1985;88(2):304-306.

23. Seto T, Seki N, Uematsu K, Tanigaki T, Shioya S, Koboyashi T, et al. Gefitinib-induced lung injury successfully treated with highdose corticosteroids. Respirology 2006;11(1):113-116.

24. Yamamoto K, Kato T, Shindo J, Ando M, Abe T, Shiraki A, et al. [A case of irinotecan or panitumumab-induced interstitial pneumonia successfully treated by steroid pulse therapy]. Gan To Kagaku Ryoho 2012;39(2):305-309. Article in Japanese.

25. Lai YC, Lin PC, Lai JI, Hsu SY, Kuo LC, Chang SC, et al. Successful treatment of erlotinib-induced acute hepatitis and acute interstitial pneumonitis with high-dose corticosteroid: a case report and literature review. Int J Clin Pharmacol Ther 2011;49(7):461-466.

26. Maher J, Daly PA. Severe bleomycin lung toxicity: reversal with high dose corticosteroids. Thorax 1993;48(1):92-94.

27. Hartmann LC, Frytak S, Richardson RL, Coles DT, Cupps RE. Lifethreatening bleomycin pulmonary toxicity with ultimate reversibility. Chest 1990;98(2):497-499.

28. Bloor AJ, Seale JR, Marcus RE. Two cases of fatal bleomycin pneumonitis complicating the treatment of non-Hodgkin's lymphoma. Clin Lab Haematol 1998;20(2):119-121. 